\title{
Nonpalpable testes: is there a relationship between ultrasonographic and operative findings?
}

\author{
Sigrid M. P. Nijs • Sebastiaan W. Eijsbouts • \\ Gerard C. Madern - Paul M. M. Leyman • \\ Maarten H. Lequin • Frans W. J. Hazebroek
}

Received: 24 October 2006 / Revised: 20 January 2007 / Accepted: 21 January 2007 / Published online: 27 February 2007

(C) Springer-Verlag 2007

\begin{abstract}
Background Ultrasonography (US) as a diagnostic tool in the work-up of boys with nonpalpable testes (NPT) is still controversial.

Objective To evaluate the relation between US and operative findings in boys with NPT.

Materials and methods During a 7-year period we saw 135 boys with 152 NPT. All were examined by the referring physician or a paediatric surgeon, underwent US examination, and were then re-examined afterwards by a specialist. Finally, all boys were surgically explored for testicular position.

Results US located 103 NPT (68\%), 16 within the abdomen and 87 in the inguinal canal. With knowledge of the US result, 37 testes were palpable on re-examination. The sensitivity of US was $97 \%$ for inguinal and $48 \%$ for abdominal viable testes. Of the 49 testes $(32 \%)$ missed by US, 16 were viable in either the abdominal $(n=14)$ or the inguinal $(n=2)$ position.

Conclusion All boys with presumed NPT should be referred to a specialist. US is useful to determine localization of NPT, which facilitates planning the surgical procedure. An inguinal exploration is called for when US
\end{abstract}

Sigrid Nijs and Sebastiaan Eijsbouts contributed equally to this work.

S. M. P. Nijs $(\bowtie) \cdot$ S. W. Eijsbouts $\cdot$ G. C. Madern •

P. M. M. Leyman · F. W. J. Hazebroek

Department of Paediatric Surgery,

Erasmus MC-Sophia Children's Hospital,

Dr. Molewaterplein 60,

3015 GJ Rotterdam, The Netherlands

e-mail: snijs0@yahoo.com

M. H. Lequin

Department of Paediatric Radiology,

Erasmus MC-Sophia Children's Hospital,

Rotterdam, The Netherlands identifies the testis in the inguinal canal. Because the sensitivity of US for viable abdominal testes is only $48 \%$, we now always perform laparoscopic exploration when US is negative.

Keywords Testes $\cdot$ Nonpalpable $\cdot$ Ultrasound $\cdot$ Children

\section{Introduction}

Failure of testicular descent is a common childhood anomaly, being seen in $0.8-2 \%$ of full-term and $18-30 \%$ of premature boys. In undescended testes (UDT) the testis fails to migrate into the processus vaginalis, failing to reach the scrotum at 35 weeks of gestation. It is unilateral in 60 $70 \%$ of cases. Approximately $20 \%$ of UDT are nonpalpable on physical examination [1]. There are four possible explanations for this phenomenon. First, the testis may be situated in the scrotum or inguinal canal, but is too small or there is too much subcutaneous adipose tissue. Second, the testis is located inside an open processus vaginalis in the inguinal canal and may be intermittently inguinal and abdominal in position. Third, it is in a true abdominal position; and fourth, the testis is lacking [2].

The literature reports that nearly half of viable nonpalpable testes (NPT) are in an abdominal position and 5\% are in the inguinal canal. The remaining $45 \%$ are atrophic or absent, mostly as a result of in utero spermatic cord torsion and are located abdominally, inguinally or scrotally $[3,4]$.

Experienced paediatric surgeons can accurately diagnose UDT by repeated and meticulous palpation of the scrotal and inguinal region. Since palpation is quite subjective, the diagnosis mostly depends on the examiner's experience and ability [2]. Currently there is controversy as to the step to take when clinical examination fails to identify a testis. 
Further exploration might be done by means of laparoscopy or by noninvasive methods such as ultrasonography (US), CT, MRI, venography or arteriography $[3,5,6]$. Of these, US is the imaging method of choice in children because it is noninvasive and does not use ionizing radiation. Furthermore, it is cheap and widely available [7].

When NPT is correctly diagnosed there is consensus on the need for early treatment, as this may decrease the risk of testicular cancer [8-12] and fertility problems [13-15]. We performed a study aimed at assessing the value of US in the diagnostic work-up of NPT, and to this end evaluated the relationship between preoperative US data and operative findings.

\section{Materials and methods}

During a 7-year period, 880 boys referred to the Department of Paediatric Surgery, Erasmus MC-Sophia Children's Hospital, Rotterdam, underwent primary surgery for UDT. US was performed in 137 of these children with 156 NPT. Prior to US the patients were clinically examined by a general practitioner, a paediatrician, a urologist or, in most cases, by a paediatric surgeon. Clinical examination by a paediatric surgeon was with the boy in the supine position, the lower half of the body undressed. The examiner placed the index finger and thumb of the right hand on either side of the inguinal canal, thus preventing testes lying distally from the inguinal canal from withdrawing into the inguinal region during palpation of the scrotum. With the examiner standing on the right side of the patient, the inguinal region was then examined with the fingertips of a warm left hand. If there seemed to be no palpable testis, an attempt was made to empty the inguinal canal by carrying out an ironing movement with the fingertips stroking in the direction of the scrotum. This may reveal a palpable testis at the level of the exit of the inguinal canal, immediately shooting back deep into the inguinal canal. If no testis could be located at all, the perineum, the base of the penis and the thigh were closely examined to exclude an ectopic testis.

US was performed using an Ultramark 9 HDI unit (Advanced Technology Laboratories, Bothell, Wash.) with a high-frequency, broadband, 7-10-MHz linear array transducer or a Philips ATL HDI 5000 unit, also with a high-frequency, broadband, 5-12-MHz linear array transducer. US was performed by eight different paediatric radiologists. After US all boys were clinically re-examined by a paediatric surgeon and again on the operating table when under anaesthesia.

Subsequently, all boys underwent surgery and testicular position and other operative findings were assessed intraoperatively.

Depending on the US results for NPT different operative procedures were used. Laparoscopy was usually performed when US could not identify a testis. In the presence of a viable abdominal testis, a one- or two-stage orchiopexy was performed. Anorchia was diagnosed when a blind-ending vas deferens was identified. When the vas deferens and testicular vessels entered the internal inguinal ring the procedure was completed by an inguinal exploration. When
Fig. 1 Ultrasound findings in 152 nonpalpable testes in relation to findings at operative exploration

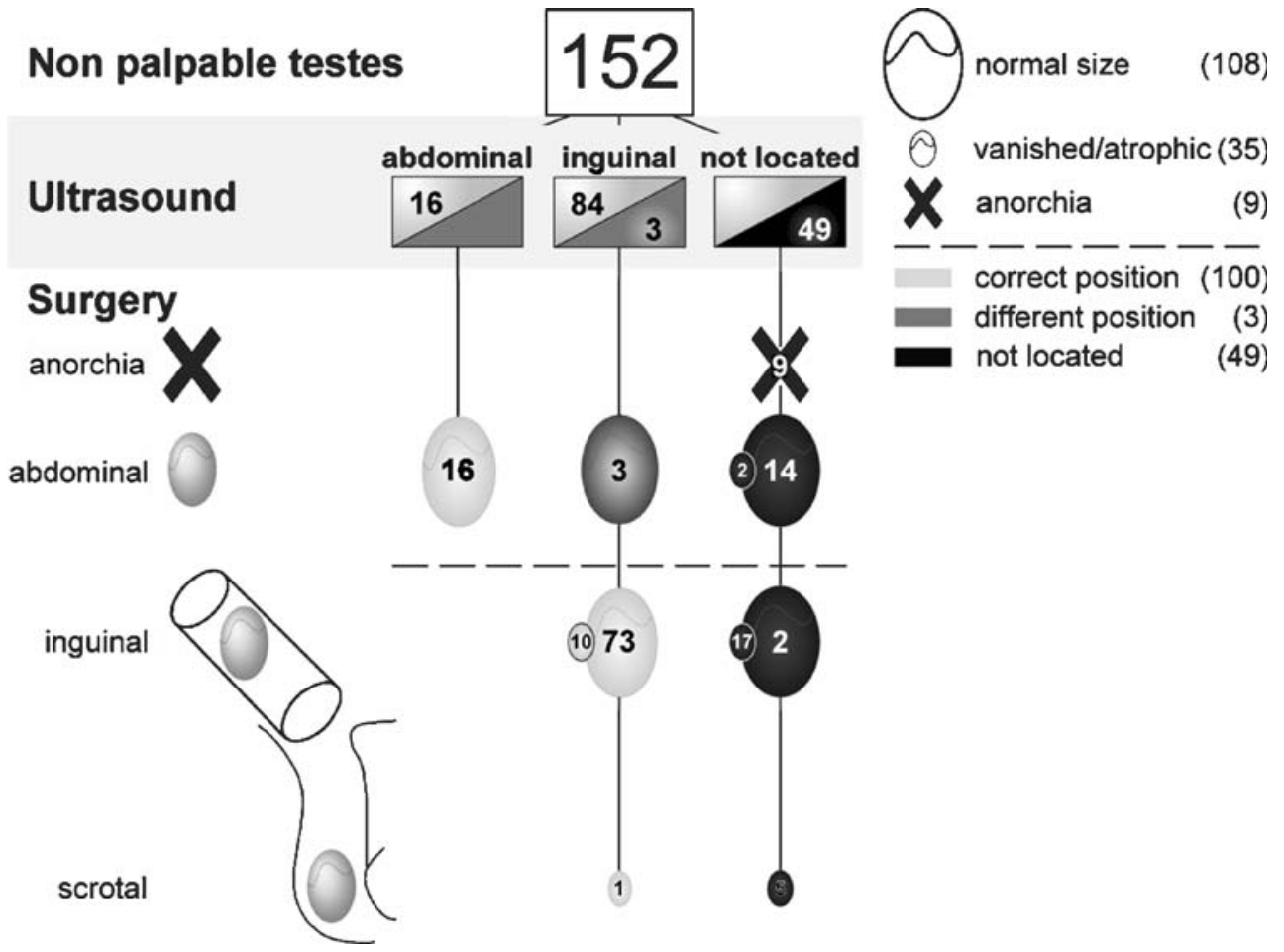




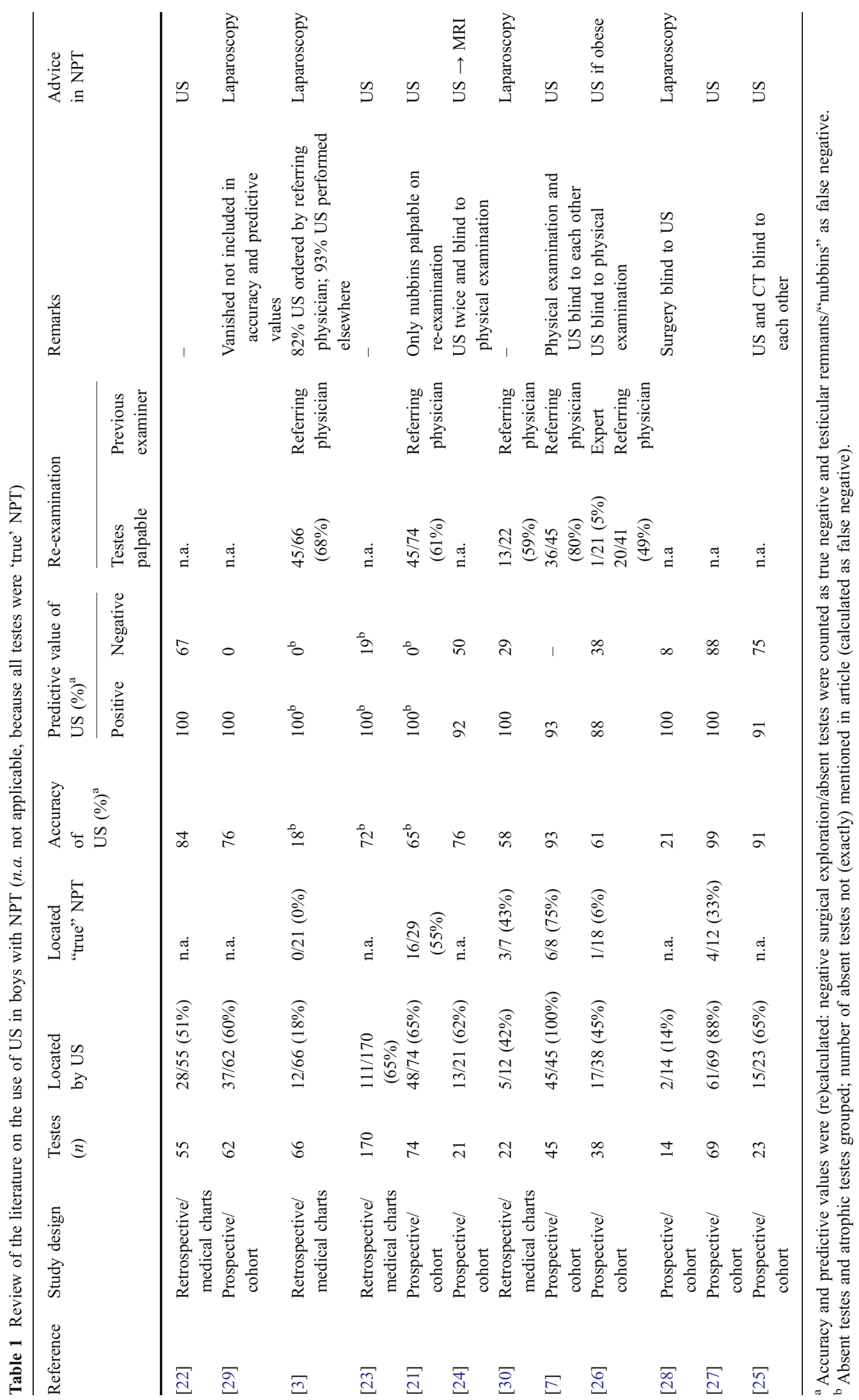


a viable testis was found, orchiopexy was performed. When a nubbin (vanished testis) or an atrophic testis was found, this was excised for pathological examination. Inguinal exploration was usually performed when US did show an inguinal testis. When a viable testis was found, orchiopexy was performed. A viable testis was defined as having a volume according to age [16].

All US findings were compared with intraoperative findings.

\section{Results}

Eligible for this study were 137 boys with 156 NPT. Excluded from analysis were two with Müllerian inhibitory factor deficiency syndrome, implying abnormal testis position. The ages of the remaining 135 boys ranged from 4 weeks to 16.2 years. Of the remaining 152 NPT, 70 were left-sided, 48 right-sided and 17 bilateral.

Four patients (four NPT) had been referred to the radiologist by a general practitioner and 24 patients (30 NPT) by a paediatrician. Most patients, 107 with 118 NPT, were first diagnosed by a paediatric surgeon before being referred to the radiologist. All boys were seen by a paediatric surgeon after the US examination for re-examination and to discuss therapy determined by the US findings.

With knowledge of the US results, $28 \%$ of the NPT previously diagnosed as not palpable now appeared to be palpable. Three of the four NPT (75\%) in patients first seen by a general practitioner were palpable when re-examined by a paediatric surgeon, as was the case for 18 of 30 NPT $(60 \%)$ referred by a paediatrician. Of the NPT first examined by a paediatric surgeon, $18 \%$ were palpable on re-examination with knowledge of the US results.

US was able to locate 103 of 152 NPT (68\%): 16 were found in the abdomen and 87 in an inguinal position; therefore 49 could not be found.
Comparing the US results with the surgical findings, there was a $100 \%$ positive predictive value (PPV) for the 16 abdominal testes seen on US; all were indeed found abdominally. Nevertheless, 14 viable abdominally located testes were missed by US. At surgery, all these testes were found in the lower abdomen - on the iliopsoas muscle, in the pelvis, or close to the internal inguinal ring. US located 87 inguinal testes, 84 of which were indeed found in the inguinal region ( $97 \% \mathrm{PPV})$; the other three were viable and found intraabdominally. Thirty-five of the NPT were defined as small, atrophic or vanished at operation.

Ultimately, US failed to locate 49 NPT. Nevertheless, 16 of these at surgery appeared to be viable, with 14 located intraabdominally and two in the inguinal region. Two atrophic testes were found in the abdomen. A further 22 atrophic testes were found inguinally or scrotally. Anorchia was present in nine boys.

In summary, $92(85 \%)$ of the 108 NPTs defined as viable at operation were located by US. While nearly all viable inguinal testes $(74 / 76)$ were correctly located by US, only half of the viable abdominal testes (16/33) were seen on US. The relevant data are summarized in Fig. 1.

\section{Discussion}

Over the years, a wide range of investigations - from vascular techniques and imaging techniques to laparoscopy - have been used in detecting NPT [17]. Inguinal exploration used to be the standard surgical approach for nonpalpable testes. If the testis was not found at or below the internal inguinal ring, the procedure was extended to the abdomen. Laparoscopy has gained greater acceptance in diagnosing and treating NPT. Cortesi et al. [18] first reported its use in 1976 in an 18-year-old adolescent. While diagnostic laparoscopy is highly sensitive in detecting NPT $[1,2,19,20]$, it carries an approximately $1 \%$ risk
Fig. 2 Flow chart representing the diagnostic and therapeutic approach in boys with NPT

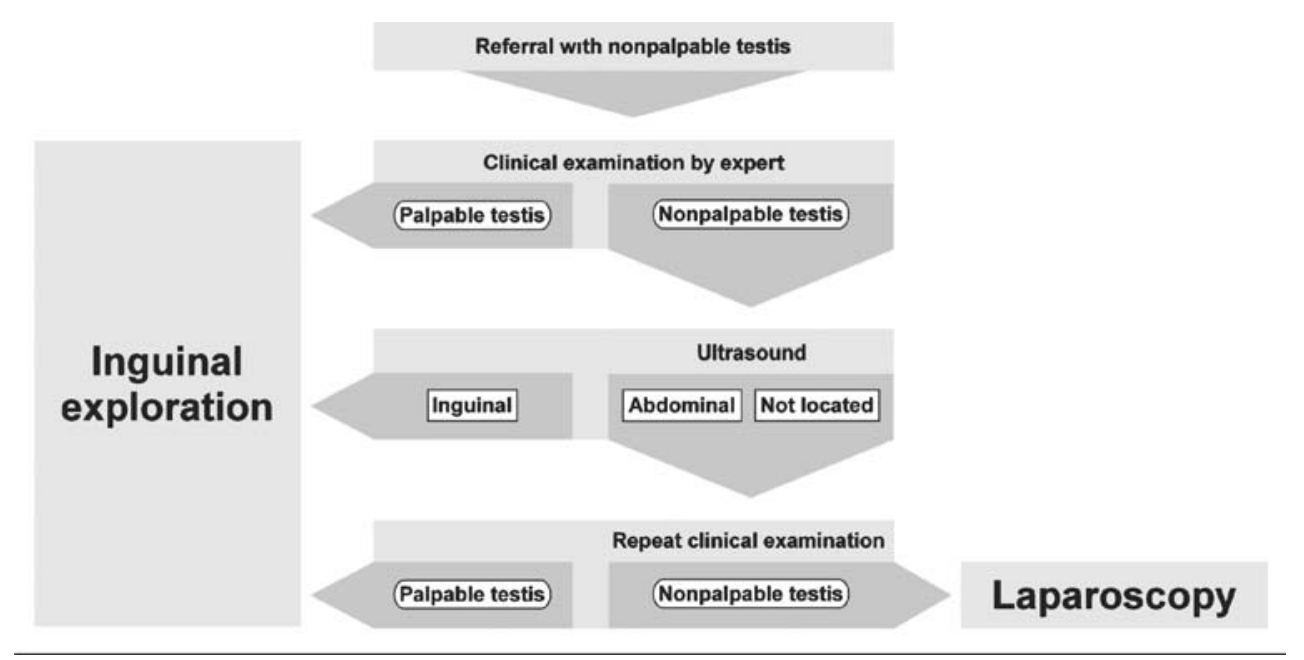


of major or minor operative complications. Furthermore, the long-term incidence of peritoneal adhesions following laparoscopic procedures in children is approximately $10 \%$ $[4,21]$.

The literature is far from unanimous on the usefulness of US in UDT. Some authors recommend US for its feasibility and potential to settle the subsequent operative procedure [7, 21-27]. Others are sceptical because they found poor outcome for NPT, and because US does not exclude the necessity for laparoscopy [3, 28-30]. Most of the studies included only small groups of patients [24-26, 28, 30]. Not all studies investigated only NPT; some included all UDT [26, 27, 30]. Most studies compared US results with findings during the operative procedure $[3,7,21,22,26-$ 29], others compared CT and/or MRI with US [23-25, 30] in relation to the operative procedure. The most relevant conclusions of these studies are summarized in Table 1.

An important message emerging from these articles is the very high PPV of US and the importance of thorough examination by a physician with experience in small genital examination. More than two-thirds of testes of referred patients were palpable on examination by experienced physicians. Many US investigations could have been avoided if patients had first been referred to an expert. The (paediatric) radiologist's experience is also vital and US should be undertaken in the hospital where further treatment will be given.

US remains the modality of choice in our centre because we value its noninvasiveness, child-friendliness and costeffectiveness. It also facilitates planning the correct surgical procedure (Fig. 2) [7, 29].

In summary, we found $97 \%$ sensitivity of US for viable inguinal testes and $48 \%$ sensitivity for viable abdominal testes. When US located a testis it was also found at that site during surgery in $97 \%$ of NPT (PPV 97\%). In our study, only three viable testes were not located correctly, being in the inguinal canal at US and within the abdomen at surgery. This can be explained by the fact that there was a patent internal inguinal ring with a mobile testis. More than two-thirds of NPT could be localized with US. Approximately one-third of NPT that were not found with US appeared to be viable at surgery. Of 34 testes considered nonpalpable by a general practitioner or paediatrician, 21 $(62 \%)$ were palpable on re-examination by a paediatric surgeon after US. In contrast, of 118 testes considered nonpalpable by a paediatric surgeon, only $21(18 \%)$ were palpable on re-examination.

\section{Conclusion}

We feel our results underpin the importance of referring boys with a presumed NPT to a physician with expertise in genital examination of small children. This will avoid unnecessary
US investigations. Furthermore, we recommend US for all boys with NPT diagnosed by an experienced physician (Fig. 2). The findings would then determine the subsequent operation: diagnostic and/or therapeutic laparoscopy for all NPT with negative US, or intraabdominal testes located by US. In addition, we recommend inguinal exploration whenever US demonstrates an inguinal testis.

Acknowledgements The authors thank J. Hagoort for editorial assistance.

\section{References}

1. Guvenc BH, Sozubir S, Ekingen G et al (2005) Advantages of video-assisted approach in detecting epididymal anomalies and treatment of nonpalpable testis. Urol Int 74:127-134

2. Gearhart JP, Jeffs RD (1988) Diagnostic maneuvers in cryptorchidism. Semin Urol 6:79-83

3. Elder JS (2002) Ultrasonography is unnecessary in evaluating boys with a nonpalpable testis. Pediatrics 110:748-751

4. Moore RG, Kavoussi LR, Bloom DA et al (1995) Postoperative adhesion formation after urological laparoscopy in the pediatric population. J Urol 153:792-795

5. Friedland GW, Chang P (1988) The role of imaging in the management of the impalpable undescended testis. AJR 151:1107-1111

6. Hinman F Jr (1987) Survey: localization and operation for nonpalpable testes. Urology 30:193-198

7. Graif M, Czerniak A, Avigad I et al (1990) High-resolution sonography of the undescended testis in childhood: an analysis of 45 cases. Isr J Med Sci 26:382-385

8. Batata MA, Whitmore WF Jr, Chu FC et al (1980) Cryptorchidism and testicular cancer. J Urol 124:382-387

9. Martin DC (1979) Germinal cell tumors of the testis after orchiopexy. J Urol 121:422-424

10. Pike MC, Chilvers C, Peckham MJ (1986) Effect of age at orchidopexy on risk of testicular cancer. Lancet 1:1246-1248

11. Pottern LM, Brown LM, Hoover RN et al (1985) Testicular cancer risk among young men: role of cryptorchidism and inguinal hernia. J Natl Cancer Inst 74:377-381

12. United Kingdom Testicular Cancer Study Group (1994) Aetiology of testicular cancer: association with congenital abnormalities, age at puberty, infertility, and exercise. Br Med J 308: 1393-1399

13. Engeler DS, Hosli PO, John H et al (2000) Early orchiopexy: prepubertal intratubular germ cell neoplasia and fertility outcome. Urology 56:144-148

14. McAleer IM, Packer MG, Kaplan GW et al (1995) Fertility index analysis in cryptorchidism. J Urol 153:1255-1258

15. Friedman RM, Lopez FJ, Tucker JA et al (1994) Fertility after cryptorchidism: a comparative analysis of early orchidopexy with and without concomitant hormonal therapy in the young male rat. J Urol 151:227-233

16. Mul D, Fredriks AM, van Buuren S et al (2001) Pubertal development in The Netherlands 1965-1997. Pediatr Res 50:479-486

17. Nguyen HT, Coakley F, Hricak H (1999) Cryptorchidism: strategies in detection. Eur Radiol 9:336-343

18. Cortesi N, Ferrari P, Zambarda E et al (1976) Diagnosis of bilateral abdominal cryptorchidism by laparoscopy. Endoscopy $8: 33-34$ 
19. Baillie CT, Fearns G, Kitteringham L et al (1998) Management of the impalpable testis: the role of laparoscopy. Arch Dis Child 79:419-422

20. Hamidinia A, Nold S, Amankwah KS (1984) Localization and treatment of nonpalpable testes. Surg Gynecol Obstet 159:439441

21. Cain MP, Garra B, Gibbons MD (1996) Scrotal-inguinal ultrasonography: a technique for identifying the nonpalpable inguinal testis without laparoscopy. J Urol 156:791-794

22. Kanemoto K, Hayashi Y, Kojima Y et al (2005) Accuracy of ultrasonography and magnetic resonance imaging in the diagnosis of non-palpable testis. Int J Urol 12:668-672

23. Liu CS, Chin TW, Wei CF (2002) Impalpable cryptorchidism a review of 170 testes. Zhonghua Yi Xue Za Zhi (Taipei) 65:6368

24. Maghnie M, Vanzulli A, Paesano P et al (1994) The accuracy of magnetic resonance imaging and ultrasonography compared with surgical findings in the localization of the undescended testis. Arch Pediatr Adolesc Med 148:699-703
25. Wolverson MK, Houttuin E, Heiberg E et al (1983) Comparison of computed tomography with high-resolution real-time ultrasound in the localization of the impalpable undescended testis. Radiology 146:133-136

26. Weiss RM, Carter AR, Rosenfield AT (1986) High resolution realtime ultrasonography in the localization of the undescended testis. J Urol 135:936-938

27. Kullendorff CM, Hederstrom E, Forsberg L (1985) Preoperative ultrasonography of the undescended testis. Scand J Urol Nephrol 19:13-15

28. Malone PS, Guiney EJ (1985) A comparison between ultrasonography and laparoscopy in localising the impalpable undescended testis. Br J Urol 57:185-186

29. Pekkafali MZ, Sahin C, Ilbey YO et al (2003) Comparison of ultrasonographic and laparoscopic findings in adult nonpalpable testes cases. Eur Urol 44:124-127

30. Hrebinko RL, Bellinger MF (1993) The limited role of imaging techniques in managing children with undescended testes. J Urol 150:458-460 